Lehtovaara, J., Heinonen, A., Lavikka, R., Ronkainen, M., Kujansuu, P., Ruohomäki, A., Örmä, M., Seppänen, O., and Peltokorpi, A. 2020. "Takt Maturity Model: From Individual Successes Towards Systemic Change in Finland.” In: Tommelein, I.D. and Daniel, E. (eds.). Proc. $28^{\text {th }}$ Annual Conference of the International Group for Lean Construction (IGLC28), Berkeley, California, USA, doi.org/10.24928/2020/0017, online at iglc.net.

\title{
TAKT MATURITY MODEL: FROM INDIVIDUAL SUCCESSES TOWARDS SYSTEMIC CHANGE IN FINLAND
}

\author{
Joonas Lehtovaara ${ }^{1}$, Aleksi Heinonen ${ }^{2}$, Rita Lavikka ${ }^{3}$, Miika Ronkainen ${ }^{4}$, \\ Pekka Kujansuu ${ }^{5}$, Anton Ruohomäki ${ }^{6}$, Maiju Örmä ${ }^{7}$, \\ Olli Seppänen ${ }^{8}$, and Antti Peltokorpi ${ }^{9}$
}

\begin{abstract}
Interest in takt production has grown globally amongst lean practitioners within the last decade. In Finland, several successful takt implementation cases within the last five years have radically increased the interest in leveraging takted production systems. However, the discussion on how to transform the first success stories of takt production to the systemic improvement of productivity has remained scarce. This study aimed to conceptualize the requirements for systemically implementing takt production within projects and organizations in the form of a maturity level model.

The study was conducted as an explorative, qualitative multiple case study. Through synthesizing the learnings of 24 takt implementation cases in Finland, we propose fifteen requirements for effectively implementing takt production, structured in the form of three maturity levels: i) technical takt planning, ii) social integration \& takt control, and iii) continuous improvement. The study has implications for the industry players and researchers to develop an understanding of where they are now and where they should focus next to improve their takt production processes to achieve a systemic change. For further research and development, the proposed model should be validated by testing the model with the industry players.
\end{abstract}

\section{KEYWORDS}

lean construction, takt production, production planning and control, continuous improvement

1 Doctoral Candidate, Department of Civil Engineering, Aalto University, Finland, joonas.lehtovaara@aalto.fi, orcid.org/0000-0002-4761-3811

2 Partner, Vison Oy, Finland, aleksi.heinonen@vison.fi, orcid.org/0000-0003-2027-9646

3 Senior Scientist, Technical Research Centre of Finland (VTT), Finland, rita.lavikka@vtt.fi, orcid.org/0000-0003-1200-4773

$4 \quad$ Business Director, Vison Oy, Finland, miika.ronkainen@vison.fi, orcid.org/0000-0002-3502-0488

5 Development Engineer, Skanska Oy, Finland, pekka.kujansuu@skanska.fi, orcid.org/0000-0002$\underline{5672-1101}$

$6 \quad$ Site Engineer, NCC Suomi Oy, Finland, anton.ruohomaki@ncc.fi, orcid.org/0000-0001-5068-5712

7 Doctoral Candidate, Department of Built Environment, Tampere University, Finland, maiju.orma@tuni.fi, orcid.org/0000-0001-5710-5266

8 Associate Professor, Department of Civil Engineering, Aalto University, Finland, olli.seppanen@aalto.fi, orcid.org/0000-0002-2008-5924

9 Assistant Professor, Department of Civil Engineering, Aalto University, Finland, antti.peltokorpi@aalto.fi, orcid.org/0000-0002-7939-6612 


\section{INTRODUCTION}

Takt production has received a large amount of attention in the lean construction community within the last decade. Takt methods such as Takt Time Planning (TTP, e.g., Frandson et al. 2013), Takt Planning and Takt Control (TPTC, e.g., Dlouhy et al. 2016) have demonstrated the potential of takted production to achieve more stable operations and radically reduced production duration, among other benefits. Successful implementation cases have been reported in various locations - especially in the US (Frandson et al. 2013), Germany (Binninger et al. 2018), and Norway (Vatne and Drevland 2016) - and most recently, in Finland (Lehtovaara et al. 2019).

Even though production systems leveraging takt have been occasionally utilized in Finland in the past, takt production has recently been considered as a basis for a systemic way (meaning that the changes affect the whole construction network) for improving production systems. International benchmarking of the best production system practices, conducted in 2016 by Industry-University consortium consisting of 19 local industry players and a university research group (Lavikka et al. 2020), has been a central catalyst for increased interest towards takt production. Moreover, research and knowledge sharing within the consortium have reinforced the national interest in applying takt production into companies' operations. The implementation results of radically decreased production duration and positive testimonials (Lavikka et al. 2020) have received a large amount of attention within the Finnish media, especially in Finland's largest construction magazine Rakennuslehti (e.g., Kivistö 2019, Mölsä 2020), further increasing the momentum within the industry.

The shared results have inspired the top management of several companies, especially the general contractors and public clients, to adopt takt production as a key aspect of their production development initiatives (Lavikka et al. 2020). In addition, designers, suppliers, and subcontractors have expressed their interest in implementing takt into their operations, as takt production has been perceived to increase their profitability and situational awareness of the production as well (Lehtovaara et al. 2019). Between 2016-2020 takt production has been utilized in dozens of projects with varied scopes and primarily positive testimonials. All in all, the resistance towards takt methods have rapidly declined within the Finnish construction industry.

However, to fully achieve the perceived benefits of takted production, a shared understanding of how to move from individual case implementations into a systemic way of implementing takt production is needed. Excluding a few pioneering clients and general contractors, the industry players do not share an understanding on which elements takt production consists of, while the academic discussion has mainly focused on how to technically implement takt production in single projects. Missing shared understanding sets a barrier for systemic, regional change that would cumulatively and collectively increase the benefits of takted production.

Forming a maturity model offers a way to drive a shared understanding of systemic takt production implementation. In addition of enabling shared understanding of a phenomenon, maturity models are widely used by organizations to compare their position in the competition, to identify focal points of development while offering a solid basis for improvement and retaining competitive advantage in the market (de Bruin et al. 2005, Mettler 2011). Also, by conceptualizing different stages of development, maturity models can enable more systemic implementation and diffusion of innovations. Maturity models have also been driving development in construction, as they are, for example, widely used 
to create a shared understanding in efforts to implement building information modeling (BIM) into projects and organizations (Liang et al. 2016).

From this basis, this study aims to conceptualize the steps for systemic implementation of takt production within projects and organizations in a regional construction ecosystem by forming a takt maturity level model. The purpose of the model is to provide takt implementers an understanding of where they are now and where they should focus next to develop their processes, to achieve the benefits of takt production in the long term. The aim is pursued by answering a research question: What are the requirements for systemically implementing takt production within construction projects and organizations?

\section{METHODOLOGY}

The study was conducted as a multiple-case study that enabled to examine the phenomena exploratively (Miles and Huberman 1994). Furthermore, the study took a grounded theory approach (Corbin and Strauss 1990) to allow the maturity model to emerge from the analyzed data. We collected qualitative data from 24 Finnish takt production implementation cases from various different project types (Table 1) between 2016 and 2020. Data collection was done through intensive observation of the cases, including the observation of planning workshops, site meetings and site visits, production documentation, and after-action reviews. While collecting data, we primarily focused on observing the planning and execution of takt plan, the takt control process, collaboration, emerging barriers, and on how takt production affected on project success in overall.

Table 1. The analyzed takt production implementation cases.

\begin{tabular}{|c|c|c|c|}
\hline Case & Project status & Project type & Key learning aspects in brief \\
\hline 1 & Finished & Commercial & Effective technical takt planning key aspect for success \\
\hline 2 & Finished & Commercial & Effective takt control with daily management key aspect for success \\
\hline 3 & Finished & Commercial & Subcontractor integration key aspect for implementing technical takt plan \\
\hline 4 & Finished & Commercial & Social integration key aspect for success \\
\hline 5 & Finished & Industrial & Effective takt planning key aspect for success \\
\hline 6 & Finished & Industrial & Effective takt planning key aspect for success \\
\hline 7 & Finished & Infrastructure & Effective takt control with daily management key aspect for success \\
\hline 8 & Finished & Infrastructure & Effective takt control with social integration key aspect for success \\
\hline 9 & Finished & Residential & Effective takt control with daily management key aspect for success \\
\hline 10 & Finished & Residential & Effective takt control with daily management key aspect for success \\
\hline 11 & Finished & Residential & Effective takt control, subcontractor integration key aspect for success \\
\hline 12 & Finished & Residential & Effective technical takt planning key aspect for success, opportunities in batch size reduction \\
\hline 13 & Finished & Residential & Effective takt planning, client integration key aspect for success \\
\hline 14 & Finished & Residential & Effective takt control, subcontractor integration key aspect for success \\
\hline 15 & Finished & Residential & Effective takt planning key aspect for success \\
\hline 16 & Finished & Residential & Effective takt planning key aspect for success \\
\hline 17 & Finished & Residential & Subcontractor integration key aspect for success \\
\hline 18 & In progress & Car Park & Opportunities in integrating subcontractors \\
\hline 19 & In progress & Commercial & Opportunities in technical takt planning in general \\
\hline 20 & In progress & Commercial & Opportunities in technical takt planning in general \\
\hline 21 & In progress & Commercial & Subcontractor integration key aspect for success \\
\hline 22 & In progress & Hospital & Opportunities in master plan integration \\
\hline 23 & In progress & Hospital & Opportunities in takting critical phases \\
\hline 24 & In progress & Infrastructure & Opportunities in batch size reduction to reduce lead time \\
\hline
\end{tabular}


Data analysis was conducted in collaboration with the authors by first mapping the most prevalent lessons learned and clustering them into larger entities. These learnings were then synthesized in the form of specific requirements, and further, structured into a form of maturity levels, forming cumulative requirements for systemically implementing takt production. After forming the maturity levels, we reflected on how the maturity levels are met in current Finnish practices. In addition, we formed three short, illustrative case examples to concretize how different requirements of the maturity levels are met in practice.

\section{PROPOSED MATURITY LEVELS FOR SYSTEMIC TAKT PRODUCTION IMPLEMENTATION}

The analysis revealed that in cases where project participants had little or no prior experience with takt production, the key drivers for success were in forming a takt plan (Cases $1,5,6,12,13,15,16,19,20,22,23,24)$. In the cases where initial takt planning was done successfully, the bottlenecks for further development focused on the social integration of parties and effective takt control (Cases 2,3,4,7,8,9,10,11,14,17,18,21). In addition to these prevalent findings, it emerged from the data (at least partially from every case) that continuous improvement over projects and over organizations was perceived as a key element in reaping the benefits of takt production in the long term. Based on these findings, the maturity levels were formed. The proposed three maturity levels and 15 requirements to achieve them are presented in Table 2 below.

Table 2: Takt maturity levels

\begin{tabular}{cc}
\hline Level i) & TECHNICAL TAKT PLANNING (project-level) \\
\hline R1 & The production plan fits the client's requirements \\
R2 & Takt areas, takt time and wagons with resourcing are unambiguously determined \\
R3 & Effective visual management is ensured \\
\hline Level ii) & SOCIAL INTEGRATION \& TAKT CONTROL (project and organizational level) \\
\hline R4 & Training and involvement of the project participants is ensured \\
R5 & The logistics are integrated and takted with the production plan \\
R6 & The design process is integrated and takted with the production plan \\
R7 & The common situational awareness during production is ensured \\
R8 & Barriers are tackled through continuous and collaborative improvement \\
R9 & Quality control is systematic and takted \\
Level iii) & CONTINUOUS IMPROVEMENT (organizational and regional level) \\
\hline R10 & Formulation and development of teams \\
R11 & Contractual integration \\
R12 & Systematic waste elimination over projects \\
R13 & Industrialized logistics and material flow \\
R14 & Standardized, takt-based work quantity libraries \\
R15 & Improving through KPl's and data-driven decision making \\
\hline
\end{tabular}

Level i) (technical takt planning) covers the requirements 1-3, which form a basis for generating a sound takt plan. Level ii) (social integration \& takt control) covers the requirements from 4 to 9 , including the involvement of supporting operations and trades 
to the planning, as well as an effective takt control. Level iii) (continuous improvement) consists of features enabling the development over individual projects, while enabling consistent productivity increase. At the moment, several Finnish companies that have attempted to implement takt production in their operations, appear to be somewhere between levels i) and ii), while also having weak signals on level iii) requirements. Level i) requirements mainly concern projects, while level ii) requirements additionally call for actions on an organizational level. Furthermore, level iii) requirements require attention on a regional level. It should also be emphasized that the requirements are cumulative, as the further levels also require that the conditions on the lower levels are consistently met.

\section{Technical Takt Planning}

The first level of maturity, technical takt planning, refers to the ability to formulate a balanced production plan that consists of takt time (the given time for a set of tasks to be completed in a takt area), takt areas (areas in which the trades work during a given takt time), and takt wagons (set of tasks that are completed in a single takt time in a single takt area). To form a theoretically sound takt plan, three requirements have to be met:

\section{$R 1$. The production plan fits the client's requirements (and is also realistic in the light of the given constraints)}

The fundamental goal of takt production is to pace the production to match the client's needs. In addition, the resourcing, production time, space utilization, and material flow are based on the constraints determined by available resources and given external constraints, forming a compromise between the most technically optimal and practically viable plan.

\section{R2. Takt areas, takt time and wagons with resourcing are balanced and unambiguously determined}

Production planning parameters are balanced to ensure a smooth flow of trades and processes, as they advance through the locations. The planning aims for optimal work sequence, minimal batch sizes, minimization of work-in-progress (WIP), optimal sizing and sequencing of areas, as well as feasible resourcing of trades (also brought up by Dlouhy et al. 2016) In addition, every actor on the site, knows where, when, and what they should do for the whole duration of the production. The intervals for tracking the production progress are also determined.

\section{R3. Effective visual management is ensured}

The plan is visualized and available for every actor on the site, which also gives information regarding the tasks and locations of other actors in the given time, enabling collaborative steering of production and tackling the emerging problems.

Several project teams in Finland have quite rapidly acquired the knowledge to perform in the maturity level one effectively. Solely forming and implementing a takt schedule (usually orchestrated by the GC) has shown excellent outcomes, resulting in $20-30 \%$ production duration reduction, especially when utilized in the interior phase. Similar results have been demonstrated in other countries, too (e.g., Vatne and Drevland 2016).

The benefit of implementing a technical takt plan surfaces from its ability to shake the traditional way of production by bringing the problems visible that have been previously buried in overly long buffer times. The visibility has forced actors to look for solutions for improvement proactively, and especially to force actors to solve problems in the planning phase that are usually issued encountered only during the production. Although 
difficult at first, while also generating stress and unforeseen sense of urgency, the project participants have generally admitted that the early handling of problems has reduced the amount of rework and quality defects, and enabled more paced and predictable production which has made takt production implementation mostly a positive experience. With smaller batch sizes (smaller takt areas and shorter takt time), the previously mentioned effects appear even more dramatically. Small batch sizes enable to find and solve the problems more effectively and allowing better control of production. On the other hand, too small buffers in relation to a high amount of variation can disrupt the flow and make production chaotic.

Achieving the level one enables the opening of the 'black box' and allows the actors to reduce variation proactively and to realize that they, indeed, have room for improvement. In cases where the requirements of technical takt planning were met, it was widely reported that to develop the process further, effective social integration and takt control are necessary.

\section{Illustrative example case 1: Tackling the emerging issues proactively with technical takt planning in repetitive construction}

Illustrative example case 1 is a residential building located in Helsinki, Finland, which utilized takt production in its indoor phase, orchestrated by the general contractor. The case building consisted of 79 rental apartments, which floor plans vary from 28 to 40.5 square meters, forming generally repetitive spaces. The indoor phase was originally scheduled for nine months. The takt area was three apartments and the takt time one day. The tasks were divided into two production trains: 1) tasks located in the apartments (excluding bathrooms) and 2) tasks located in the bathrooms. In total, the first train included 40 wagons and the second train 20 wagons.

The takt control, however, did not fully proceed throughout the production according to one-piece flow principles. The flow was often interrupted, and the production suffered from problems with materials such as delayed or too early deliveries, contradicting objectives with the subcontractors, and lack of communication. Nevertheless, since the takt planning was executed at such a detailed level, occurring issues and challenges were detected in the early stages (requirements R1, R2). The detailed planning allowed the site management to react to problems before they cascaded to other wagons (R3).

Even with challenges in takt control, the case resulted in apartments finishing with improved quality, with more gained profit for the contractor and finish within the given schedule. The finished apartments had only minor or no flaws, and the average time to repair the defects was 15-20 minutes per apartment, which was also reflected on dramatically reduced go-back work. Furthermore, the use of takt production reduced the duration of the interior phase from the originally scheduled nine months to eight months. The site personnel argued that an additional one month of time reduction would have been possible if it had been necessary. In addition, the general contractor was able to gain over 40 percent more profits than initially targeted, mainly due to the decreased duration and better quality. In conclusion, the illustrative example case was able to achieve the requirements on maturity level i).

\section{SOCIAL INTEGRATION \& TAKT CONTROL}

The second level of maturity, social integration \& takt control, refers to the ability to integrate supporting operations and trades to the planning, with effectively controlling the production within takted pace. Takt control consists of tight production control operated through daily production meetings (daily huddles), with a primary aim of achieving 
steady hand-offs between wagons at the end of every takt time (Frandson et al. 2013). The second level of readiness consists in total of six requirements:

\section{R4. Training and involvement of the project participants is ensured}

Project participants, especially trade heads and workers, are trained to succeed with takt production. The participants are involved in the planning to utilize their expertise (also mentioned by Tommelein 2017), and to engage them with the takt plan. The involvement requires that the preliminary plan is formed before and continued in parallel with procurement operations.

\section{R5. The logistics are integrated and takted with the production plan}

Material deliveries to the site, storage and hauling of the material on the site are planned, buffered, and managed in a way that materials are available for every takt in time (also suggested by Lehtovaara et al. 2019).

\section{R6. The design process is integrated and takted with the production plan}

The designs are provided and checked beforehand for every takt in time. The constructability is ensured with the trades before given takt to achieve an uninterrupted information flow during the production.

\section{$\mathbf{R} 7$. The common situational awareness during production is ensured}

Situational awareness (up-to-date information regarding the production status) is shared amongst every actor on the site, enabling daily, visual, and collaborative management. The progress of the takt plan is checked in the pace of takt, and the plan is updated at the agreed intervals.

\section{R8. Barriers are tackled through continuous and collaborative improvement}

Obstacles for work are reported and solved in collaboration, at a minimum, with the pace of takt. Actions for improvement, such as balancing resources or adding buffers, are agreed and conducted in agreement with the participants the actions affect.

\section{R9. Quality control is systematic and takted}

Quality is controlled through systematic hand-offs between wagons in the pace of takt time. The control diminishes the need for rework and minimizes quality defects over time as the initial defects are immediately fixed and prevented in the following takts.

Even though several Finnish general contractors have formed their way of conducting takt plans, the integration of other project participants and supporting activities to the production plan as well as effectively controlling the production are not well established. While creating a technical takt plan forms a prerequisite for successful production, it does not single-handedly guarantee success. As takt production is often seen solely as a scheduling process instead of a holistic way of planning and controlling production, GCled attempts often overlook the need to start takt planning in parallel with design and procurement operations, while also opting for traditional firefighting over systemic and takted production control.

The need for social integration has been especially noted in more complex projects, such as hospital construction. For example, enabling the production flow between MEP and structural works is not easily achieved, if the knowledge of the trades, material suppliers, and designers is not utilized in the planning process. However, even in the simplest production settings, it has been noted that the involvement and more thorough training of project participants yields significantly better results. As long as the 
construction process remains fragmented, holistic integration is essential for achieving the full potential of takt production, as well as inspiring designers, suppliers, and trades to be involved in development while also sharing the benefits of takt equally.

Achieving level two enables the collaborative solving of the problems that the technical takt planning has brought into awareness, as well as exploiting the rhythm of takt in production control. However, staying in level two only enables limited improvement over projects.

\section{Illustrative example case 2: Achieving stability and commitment with collaborative takt planning and control in non-repetitive construction}

The second illustrative example case is a 40000 square-meter, a multi-story office building in Helsinki. The case used a 5-day takt partially for the interior phase of the project. The takt production was implemented to MEP (Mechanical, Electrical and Plumbing) works for a single section of the building, which was determined as a bottleneck for the whole project. The motive to utilize takt production was to decrease production duration as well as to stabilize production to reduce the risks for cost and schedule overruns. To achieve the objectives, deeper collaboration between the general contractor and trades was perceived as a critical success factor (Figure 1).

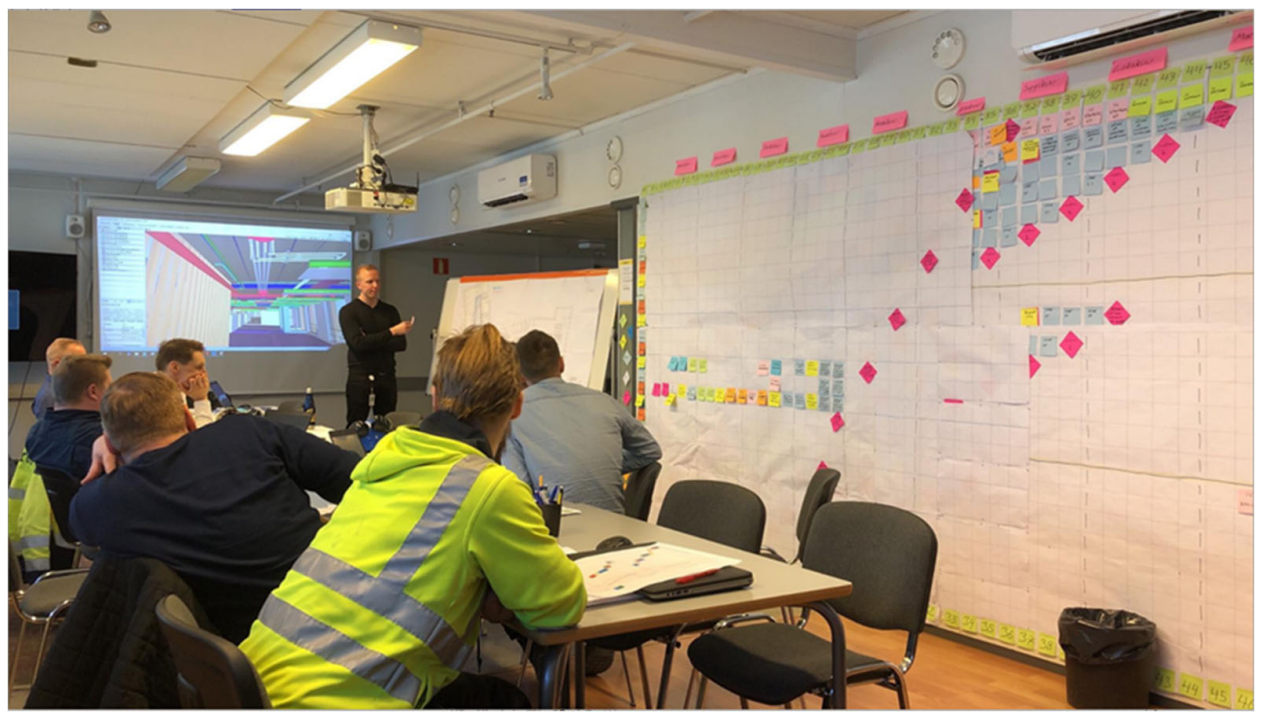

Figure 1: Takt production planning workshop with trades

The process to formulate the takt plan was based on the six-step method by Frandson et al. (2013), while the planning was conducted in collaboration with the subcontractors (R4) during multiple workshops that also utilized collaborative pull-planning. The takt control was maintained with daily huddles and weekly contractor meetings. The atmosphere in the daily huddles and contractor meetings was pleased due to well-organized production (R7, R8) even though the start of the takt production had some setbacks with takt area handovers (partially missing R9). It was also noted that occasional unregular updating of takt plan led to a lost situational awareness and partially reactive control of production, which additionally demonstrated the need for continuous control. Furthermore, in addition to integrating subcontractors the process, integration of design management and logistics could have yielded even better outcomes (missing R5, R6).

Even though utilizing takt production did not reduce the production duration remarkably, collaborative planning and control of the critical section enabled more stable 
production and handover of the complex project, which was the second goal for takt production implementation. In addition to finishing the bottleneck tasks during the given takts, effective takt control also enabled better steering of the related, non-takted tasks within the section. It was perceived among the project participants that the collaborative takt planning and control largely contributed to the success of the complex project. In conclusion, illustrative example case 2 was able to achieve some of the requirements on maturity level ii).

\section{CONTINUOUS IMPROVEMENT}

The third level of maturity, continuous improvement, refers to the ability to collectively learn and develop the operations over individual projects and organizations. The third level of maturity consists in total of six requirements:

\section{R10. Formulation and development of teams}

Partnerships over projects are formed that enable the development of consistent teams. Knowledge acquired from previous projects is transferred from the knowledge of individuals to knowledge of teams, and further for the following projects.

\section{R11. Contractual integration}

Contract models allow the integration of different parties to support the means of takt production, for example, by enabling the integration of key parties (such as contractors, designers) early on to the project, and by enabling the allocation of risks and benefits adequately between project organizations.

\section{R12. Systematic waste elimination over projects}

Standardized methods for root-cause analyses and systematic elimination of waste are enabled with collaboratively used tools such as A3 reports. The learnings are systematically stored and further used in the following projects.

\section{R13. Industrialized logistics and material flow}

Location-based bill of materials (BOM) is utilized to enable the tracking of material consumption and continuous waste elimination. Logistics, material, and waste management are separated from value-adding work, by for example, utilizing a logistics operator that manager the material flow. (also suggested by Tetik et al. 2019)

\section{R14. Standardized, takt-based work quantity libraries}

The performance of the teams is tracked and stored, forming a baseline to effectively form reliable takt plans in the following projects and enabling continuous improvement.

\section{R15. Improving through KPI's and data-driven decision making}

The most important, business-related production key performance indicators (KPI's), such as lead time, throughput time, and amount of quality defects, are determined, measurement and evaluated to enable meaningful alignment of improvement actions. Data are systematically collected to enable improvement based on facts, not just opinions.

Even though the continuous improvement of takted production has not been systemically implemented over projects yet, the findings indicated for the enormous potential of continuous improvement. Achieving level three enables the continuous improvement of the issues that are initially solved within individual projects, allowing sustained growth. 


\section{Illustrative example case 3: Demonstration of the potential of systemic data collection and improvement in repetitive renovation construction}

Illustrative example case 3, located in Helsinki Finland, constituted three separate office buildings that were built in three different phases between the years $1901-1981$ and were renovated and transformed into a hotel, containing altogether 148 hotel rooms. One of the buildings (75 hotel rooms) was executed with takt production with two different production trains both utilizing 1-day takt: first for the hotel room bathrooms (takt area one bathroom) and the second for the rest of the hotel room (takt area rest of the hotel room). The process of implementing takt production demonstrated quite well the capability to perform within maturity level i) and partially in level ii). After the first blank of the takt schedule, subcontractors were included in the takt planning, and the plan was adjusted by the suggestions of the subcontractors. In addition, steps for daily takt control were defined in collaboration.

During the implementation, the production was analyzed by recording video for two weeks from two different hotel rooms to calculate the utilization rates of the hotel rooms in the takt production. Also, systematic observation of the workers was made during the measuring period. The observed utilization rate of the rooms was $37 \%$ (planned utilization rate $43 \%$ ) of the working time during the measuring period, and almost all the scheduled tasks which were planned to do on that period were finished. However, a surprising finding from the video data was that there was a lot of unnecessary movement in the takt areas (Table 3). During the measuring period, there were 1590 entries in the two measured hotel rooms, which means, on average, 79.5 entries in the $20 \mathrm{~m}^{2}$-sized hotel room per day. It was also found out that the time of the presence in the takt areas had a lot of variation, and most of the presences were relatively short - only for a few seconds. Observation also exposed that the takt control was defective because the planned daily huddle meetings were not kept almost without exceptions. Defective takt control and the undefined workable backlogs were interpreted as reasons for the unnecessary movement and the variation on it, which were concluded to be a result of lack in the workers' situational awareness of the production.

Table 3: Number of visits and number of workers entered to the observed takt areas

\begin{tabular}{|c|c|c|c|c|c|c|c|c|}
\hline \multirow[b]{2}{*}{ Day } & \multirow[b]{2}{*}{ Visits } & \multicolumn{4}{|c|}{ Room 1} & \multicolumn{3}{|c|}{ Room 2} \\
\hline & & $\begin{array}{l}\text { Avg. visit } \\
\text { time }\end{array}$ & $\begin{array}{l}\text { St.dev. } \\
\text { of visits }\end{array}$ & $\begin{array}{c}\text { Amount of } \\
\text { different } \\
\text { workers }\end{array}$ & Visits & $\begin{array}{l}\text { Avg. visit } \\
\text { time }\end{array}$ & $\begin{array}{l}\text { St.dev } \\
\text { of visits }\end{array}$ & $\begin{array}{c}\text { Amount of } \\
\text { different } \\
\text { workers }\end{array}$ \\
\hline 1 & 103 & 0:03:27 & 0:06:41 & 13 & 133 & $0: 02: 10$ & 0:04:19 & 14 \\
\hline 2 & 82 & 0:01:58 & 0:06:03 & 12 & 72 & $0: 03: 22$ & 0:09:41 & 17 \\
\hline 3 & 76 & 0:01:28 & 0:04:44 & 18 & 89 & 0:01:06 & 0:02:29 & 24 \\
\hline 4 & 78 & 0:01:05 & 0:02:06 & 13 & 63 & 0:01:38 & 0:04:45 & 18 \\
\hline 5 & 50 & $0: 02: 38$ & 0:08:45 & 7 & 65 & $0: 02: 17$ & 0:08:41 & 14 \\
\hline 6 & 81 & 0:04:43 & $0: 11: 28$ & 14 & 62 & $0: 02: 02$ & 0:03:58 & 10 \\
\hline 7 & 76 & 0:02:54 & $0: 06: 12$ & 15 & 67 & 0:04:47 & $0: 10: 58$ & 14 \\
\hline 8 & 105 & 0:01:38 & 0:04:34 & 18 & 102 & $0: 02: 14$ & 0:06:38 & 10 \\
\hline 9 & 89 & $0: 01: 25$ & $0: 02: 47$ & 21 & 105 & 0:03:32 & $0: 10: 25$ & 12 \\
\hline 10 & 36 & 0:02:19 & $0: 04: 26$ & 14 & 56 & 0:02:04 & 0:05:46 & 9 \\
\hline
\end{tabular}


Even though the observed production period was treated as a successful, and planned tasks were all finished within the observation period, the data analysis revealed room for a large amount of improvement. Even though 1-day takt schedule was seen as 'tight', the production goals were met with only $37 \%$ utilization rate of space, and the workers were able to finish their work even though analysis revealed that they were most of the time running from location to another, barely staying a few minutes in a single location. By improving the prerequisites over projects to enable the workers to work uninterruptedly in one location, the productivity could be dramatically improved in the next takt production implementations. Even though not straightly demonstrated in the case, it was perceived that systemic data collection and analysis is needed in achieving requirements $\mathrm{R} 12, \mathrm{R} 14$, and R15.

\section{CONCLUSIONS}

The aim of the study was to conceptualize the requirements for systemic implementation of takt production within projects and organizations in the form of a maturity level model. In Finland, the companies have been able to gain quick benefits through effective technical takt planning. However, even though forming a technically sound takt plan is the first step in implementing takt production, we suggest that Finnish construction companies should next look into the social integration of the key project parties as well as effective takt control. To achieve the full potential of takt production, a continuous improvement over projects and organizations is also needed.

The study has implications for the researchers and industry players to develop an understanding of where the organizations are now and where they should focus next to improve their takt production practices. For further research, the proposed model should be validated by testing the model with the industry players. The model could also be utilized in other geographical areas; however, as the results are based on an analysis of an individual geographical location, validation is needed. In addition, a longitudinal study could be conducted to address how following the maturity levels would affect the success of projects and organizations in the long term, guiding them towards a systemic change.

\section{ACKNOWLEDGMENTS}

The research was supported by the Building 2030 consortium of Aalto University and 19 companies. www.building2030.com

\section{REFERENCES}

Binninger, M., Dlouhy, J., Müller, M., Schattmann, M. and Haghsheno, S. 2018. "Short Takt Time in Construction - a Practical Study". Proc. (IGLC 26). Chennai, India.

De Bruin, T., Rosemann, M., Freeze, R., and Kaulkarni, U. 2005. "Understanding the main phases of developing a maturity assessment model." Proceedings (ACIS) Australasian Chapter of the Association for Information Systems.

Dlouhy, J., Binninger, M., Oprach, S. and Haghsheno, S. 2016. "Three-Level Method of Takt Planning and Takt Control - a New Approach for Designing Production Systems in Construction." Proceedings (IGLC 24). Boston, USA.

Frandson, A., Berghede, K. and Tommelein, I. 2013. "Takt Time Planning for Construction of Exterior Cladding." Proceedings (IGLC 21). Fortaleza, Brazil. 
Kivistö, T. 2019. "Rakentamisessa on löytymässä uusi tahti." Rakennuslehti, $<$ https://www.rakennuslehti.fi/blogit/rakentamisessa-on-loytymassa-uusi-tahti/> (January 11, 2019).

Lavikka, R., Seppänen, O., Peltokorpi, A., and Lehtovaara, J. 2020. "Fostering process innovations in construction through industry-university consortium." Construction Innovation., Vol. and No. Ahead-of-print.

Lehtovaara, J., Mustonen, I., Peuronen, P., Seppänen, O. and Peltokorpi, A. 2019. "Implementing Takt Planning and Takt Control Into Residential Construction." Proceedings (IGLC 27). Dublin, Ireland.

Liang, C., Lu, W., Rowlinson, S., and Zhang, X. 2016. "Development of a multifunctional BIM maturity model." Journal of construction engineering and management, 142(11).

Mettler, T. 2011. "Maturity assessment models: a design science research approach." International Journal of Society Systems Science (IJSSS), 3(1/2).

Miles, M., and Huberman, A. 1994. "Qualitative data analysis: An expanded sourcebook." Sage.

Mölsä, S. 2019. "Onko tahtituotanto työmaalle riski? 25 mestarin kokemukset kertovat joustavuudesta ja laadun paranemisesta." Rakennuslehti, $<$ www.rakennuslehti.fi/2019/11/onko-tahtituotanto-joustamaton-riskikokeilubuilding-2030-testasi-asian-pilottiprojekteissa/> (January 11, 2020).

Corbin, J., and Strauss, A. 1990. "Grounded theory research: Procedures, canons, and evaluative criteria." Qualitative sociology. 13(1).

Tetik, M., Peltokorpi, A., Seppänen, O., Viitanen, A. and Lehtovaara, J. 2019. "Combining Takt Production with Industrialized Logistics in Construction." Proceedings (IGLC 27). Dublin, Ireland.

Tommelein, I. 2017. "Collaborative Takt Time Planning of Non-Repetitive Work." Proceedings (IGLC 25). Heraklion, Greece.

Vatne, M. and Drevland, F. 2016. "Practical Benefits of Using Takt Time Planning: A Case Study." Proceedings (IGLC 24). Boston, USA. 